InOdia $\quad \begin{aligned} & \text { InMedia } \\ & \text { The French Journal of Media Studies }\end{aligned}$

7.2. $\mid 2019$

Documentary and Entertainment

\title{
David Roche, Quentin Tarantino: Poetics and Politics of Cinematic Metafiction
}

Jackson: University Press of Mississippi, 2018

Hervé Mayer

\section{(2) OpenEdition}

\section{Journals}

Electronic version

URL: http://journals.openedition.org/inmedia/1830

DOI: $10.4000 /$ inmedia. 1830

ISSN: 2259-4728

Publisher

Center for Research on the English-Speaking World (CREW)

Printed version

Date of publication: 15 December 2019

\section{Electronic reference}

Hervé Mayer, "David Roche, Quentin Tarantino: Poetics and Politics of Cinematic Metafiction", InMedia

[Online], 7.2. | 2019, Online since, connection on 27 January 2021. URL: http://

journals.openedition.org/inmedia/1830 ; DOI: https://doi.org/10.4000/inmedia.1830

This text was automatically generated on 27 January 2021

(C) InMedia 


\title{
David Roche, Quentin Tarantino: Poetics and Politics of Cinematic Metafiction
}

\author{
Jackson: University Press of Mississippi, 2018
}

Hervé Mayer

\section{REFERENCES}

David Roche, Quentin Tarantino: Poetics and Politics of Cinematic Metafiction, Jackson: University Press of Mississippi, 2018

David Roche's book-length study of the eight films directed by Quentin Tarantino (up to The Hateful Eight, 2015) is a stimulating exploration of the aesthetic complexity and political depth of the contemporary auteur's oeuvre. Throughout its eight thematic chapters, Roche's book meticulously builds up on a relatively limited corpus of existing research on the director's work (on history, intertextuality, race, and violence), and opens up new areas of enquiry (on narrative experimentation, visual style, theatricality, and the use of music), to propose a convincing reading of Tarantino's work as "cinematic metafiction". The author argues that Tarantino's films, rather than being solipsistic, use intertextuality and reflexivity to "engage with culture politically and morally through a critical engagement with the medium and its history" (5). References to film history, cultural history and the director's previous films are not just meant to be playful, postmodern winks, but constitute the foundation of meaningproduction at the narrative and political levels, and invite viewers to engage with the history of representations and with real-world concerns.

2 The introduction serves to situate Tarantino's work and its reception, and define the theoretical framework of the study. It reminds the reader that Tarantino is a selftaught director whose creative framework stems from an ongoing engagement with culture, high and low, and film as a medium. Such engagement results in films that are 
highly intertextual, but whose intertextuality serves to produce meaning and invite viewer participation. Discussing the distinction between reflexivity (Robert Stam), metafilm (Marc Cerisuelo), metacinema (Fatima Chinita) and metafiction (Linda Hutcheon and Patricia Waugh), Roche chooses the term "cinematic metafiction" to describe Tarantino's films, which he defines as cinematic fiction that "engages with its status as a work of fiction by producing a meta-discourse that can be explicit, implicit or, more often, an alliance of both" (9). Metafiction, regardless of the medium, engages with the relationship between fiction and reality, and Tarantino's films reference film and cultural history to invite connections with the real world.

3 Borrowing its title from Colonel Landa's line in Inglorious Basterds, "What Shall the History Books Read?", the first chapter deals with history and film history in the films of Tarantino, focusing on the director's use of historical material in Inglorious Basterds, Django Unchained and The Hateful Eight. Roche argues that these three films are firmly anchored in history, with references to actual settings, events and people, as well as film history, with overt or covert connections to film genres, styles and characters. The interplay of fictional and historical referents along with a creative relationship to history, resorting to inventions, anachronisms and inaccuracies, serve to highlight the constructed nature of historical discourse as well as the films' own nature as allohistorical fantasies (presenting an alternate version of history). As fantasies that address political and ethical issues, these films take on an allegorical dimension that broadens the historical and geographical scope of their critical potential, inviting connections with both past and present. To viewers who choose to investigate these connections, they provide new perspectives on a history of violence (race exploitation, anti-Semitism and racism) but also suggest the persistence of that violence in the present. Their conscious inscription in film history allows the films to explore the political implications of culture in representing the past and its power to shape attitudes in the present. As such, they provide "a defense of metafictional cinema as ethically and politically engaged with real-world concerns" (31).

4 The second and third chapters, "Black Man, White Hell" and "That's the Excuse You Guys Use Whenever You Want to Exclude Me from Something", deal with identity politics in the films of Tarantino, respectively race and ethnicity, and gender and sexuality. Although Roche separates race and gender in different chapters for the sake of clarity, he constructs both chapters along the same outline (genre conventions, power relations, language, bodies) and multiplies cross-references so as to emphasize how those related aspects of identity intersect in the films of Tarantino. The director represents the various aspects of identity politics as "social constructs caught up in normative discourses and practices that have a history and a context" (34) and hybridizes film genres to destabilize these constructs and suggest transformative perspectives. Impurity, intertextuality and trans-genericity thus serve to establish the films and their main protagonists as sites of transformative potential. Roche's discussions on race and ethnicity build upon Adilifu Nama's Race on the QT (University of Texas Press, 2015) and confirm the latter's assertion that race is an organizing principle in Tarantino's films, which are constructed as "problematized engagements with racial politics" (74). The developments on gender and sexuality reveal the impact of Tarantino's interest in feminist film theory on his films' deconstruction of gendered conventions and categories, but they also identify male homosexuality as a blind spot in the films' exploration of identity politics. All in all, Roche demonstrates how the films "are highly self-conscious of the gendered and racialized terms of the genres they 
rework, of the history and historiography of representations in film and cultural history" (124). They develop a criticism of the cultural stereotypes constructed by Hollywood, explore the past and present centrality of race and gender in power relations, interrogate the role of racist and sexist language to construct the identity of the subject in opposition to an other, and approach whiteness and masculinity as racialized and gendered constructions. Although the films belie the existence of a postracial or post-feminist world, they maintain hope by celebrating interracial relationships and a "female form of empowerment" mixing qualities across gender boundaries (125).

5 Entitled "Revenge Is Never a Straight Line" and "Everything's the Same Except for One Change", the fourth and fifth chapters apply a neoformalist approach to Tarantino's work, focusing on narrative structures and paradigms, then on narration and style. The two chapters provide an in-depth study of the films' peculiar structures, modes of narration, aesthetics, and signature style. Alternating analyses of individual films with discussions of the whole body of Tarantino's work, proceeding thematically and formally through the films, contrasting the use of various profilmic or cinematic devices across the films, and constantly revealing how aesthetic features impact the narrative, these chapters demonstrate that Tarantino's stylistic and narrative choices, as well as the numerous reflexive devices and intertextual references present in his films, are never gratuitous or merely playful, but always serve the production of meaning, both narrative and political. Roche demonstrates that Tarantino's narration and style are mainly indebted to classical Hollywood, with an art-cinema influence that allows the director to deconstruct and resignify Hollywood storytelling conventions. In that sense, Tarantino's filmmaking is heir to the New Hollywood and 1980s and 1990s US indie cinema that drew on European new waves, exploitation cinema, Italian Westerns, or martial arts movies to question and reinvigorate classical Hollywood. The various borrowings from all cinemas allow the director to celebrate the wealth and diversity of cinematic creation, while the resignification of the referents critically points out the limitations of the source material, with political implications. Such approach to filmmaking conceives creation "as a reprisal with variation, and thus as recreation" (222), with the one change bringing old formulas, conventions, and practices into new light.

6 Chapter 6, "Lookin' Back On the Track, Gonna Do It My Way", focuses on the use of preexisting music, Tarantino's main approach to soundtrack which contributed to "constructing the director's persona as a historian of pop culture" (224). The films' use of preexisting music is quite consistent with the common functions of music in film - to support and comment upon characterization and narrative, to establish and complexify atmosphere and rhythm - but preexisting music also contributes to the development of a metafictional discourse on creation and its cultural and political implications. Often selected during the screenwriting process (with such selection process being foregrounded in the films themselves), these preexisting pieces are part and parcel of Tarantino's process of creation (and of its mise en abîme in his films). Often recent covers of old songs, and often cropped and tailored to fit a scene, they serve to blur the notion of original material and celebrate Tarantino's conception of creation as recreation. Mainly taken from film or TV soundtracks, they establish an intertextual network of meanings - exploring generic identity or an actor's star image - that can be used to complexify a film's subtext and comment upon both the present films and their past referents. Preexisting music has specific signifying power because it taps into 
cultural memory - "it is music with baggage" - so that its use implies "that the acts of both creation and interpretation are inevitably back-and-forth processes" (240) between track and film, original and cover, musical and film genre. The chapter concludes with a note on the use of 'original' music, written specifically for a film (RZA and Robert Rodriguez in Kill Bill; John Legend, Anthony Hamilton, Rick Ross and others in Django Unchained; Ennio Morricone in The Hateful Eight), arguing that its use is either subordinate to preexisting music (Kill Bill), ends up fashioning the film in similar ways (Django Unchained), or is given similar structural, rhythmic, and narrative functions (The Hateful Eight).

7 Entitled "Come On, Let's Get Into Character", chapter seven focuses on acting and theatricality. Present in various degrees in all of Tarantino's films, theatricality is a central element "that serves to frame the films' metafictional discourses on acting, transposing the theatrum mundi metaphor to film" (245). A modality of reflexivity, theatricality is first achieved through the handling of space and its exploitation in connection with the narrative. Staging, the division of space, the structuration of the narrative around the entrance and exits of characters, the use of props and various aesthetic and stylistic choices (frontality, deep focus, frame within the frame) serve to lay bare the artifice and create spaces for the actors' movements. Tarantino's practices in casting and the direction of actors also contribute to theatricality. The director uses lead and supporting actors often associated with one genre or iconic roles, exploits their star image to engage with film and cultural history, and integrates a reflection on typecasting and direction in his films - most noticeably through his cameos and through the use of recurring actors, the latter also contributing to intertextuality within his oeuvre. Choices in the direction of actors serve to contrast naturalistic and theatrical acting styles within films and scenes and often invert Hollywood conventions by placing the latter center-stage. Acting is itself overtly thematized, approached through questions of duplicity, professionalism, and role-playing. The films often highlight the dangers of breaking, or sticking to, character and favor instead "an ethical subject asserting her/his values by adapting her/his roles" (268).

The final chapter, "He's Just Not Used to Seein' a Man Ripped Apart by Dogs Is All", discusses violence, spectacle, and their relationship in Tarantino's films, aspects that have attracted more attention - and criticism - from reviewers and researchers. Roche argues that violence is never gratuitous and merely cathartic, but rather consistently provides a metafictional commentary on the treatment of violence as spectacle in fiction films. Although scenes of violence are relatively sparse and short (excepting Kill Bill), violence is a central characteristic of Tarantino's films because it "stands at the nexus of aesthetics, ethics and politics" (287). The director's treatment of violence alternates between the aesthetics of suggestion and monstration (275), which are usually distributed in relation to the ethics and politics of the violent acts - a restrained approach in more problematic scenes, in which the victim is recognized as an imagined human being; an excessive approach in less problematic scenes, in which bodies are treated as cinematic material). The fact that such distribution is not systematic, with each scene begging to be viewed on its own terms, points to the notion that violence is a complex that must be analyzed in context. This complexity is reflected in the films providing catharses that are always "limited and nuanced" (279), mixing blockbuster spectacle and art-cinema commentary to taint even the more pleasurable scenes with moral compromise. The thematization of violence as spectacle further develops a metafictional discourse on the ethics of violence, the position of the viewer, and 
spectatorial responses to violent spectacle, eventually revealing ethical and political questions in all their complexity.

The conclusion returns to the book's premise, asserting the inscription of Tarantino's films in a long tradition of anti-illusionist fiction, recalling that their engagement with film history presupposes a dialogical relationship between culture and history, and concluding that "the poetics and politics of Tarantino's cinematic metafictions intersect because the politics of representation are intertwined with the aesthetics of re-creation" (289). The director's privileged relationship to the Italian Western makes sense precisely because the Italian Western is itself a derivative and a re-appropriation, glorifying the conventions of the Hollywood genre while undermining its ethics and resignifying its politics. Tarantino's films do exactly that: "recycle[e] to resignify" (291) and "celebrate the beauty of the icon while undercutting it" (292). They are characterized by their active engagement with contemporary issues of historical and transnational circulations, originality and copy in art, the performativeness and performance of identities. They are also characterized by their layeredness, their remixing and fusing of high art and pop culture across borders and industries, and their striving for an ideal blend of efficacy, spectacle and sophistication that can regenerate cinema.

Well-written and well-documented, David Roche's contribution to the study of Quentin Tarantino's work may be the best book to date on the iconic director. Roche's obvious passion for his material does not preclude rigorous analysis, but rather serves it, driving his desire to critically engage with the films while drawing the reader in in the process. The quality and precision of formal analyses are exemplary, while the demonstrations are led with clarity and taken to astute conclusions. Some of the chapters (on music, on theatricality, on violence) are less fully developed, but their nuanced developments are an invitation to further research. The book contains a filmography section with basic information on the films of Tarantino, a thematic bibliography (books and articles on Tarantino; film criticism and theory; general criticism and theory) and a generous index section.

\section{AUTHORS}

\section{HERVÉ MAYER}

Université Paul-Valéry Montpellier 3 